\title{
Measuring consumer preference for models of diabetes care delivered by pharmacists
}

\author{
Susan TAYLOR, Fleur HOURIHAN, Ines KRASS, Carol ARMOUR. \\ Received (first version): 12-Jun-2009 Accepted: 20-Oct-2009
}

\begin{abstract}
${ }^{*}$
Evaluation of a community pharmacy disease management program for type 2 diabetes, 'SugarCare', was conducted. Compared with the standard care offered by pharmacists, this enhanced program offered patients closer monitoring of blood glucose levels, counselling about lifestyle, etc. The SugarCare study was funded by a grant but if the care is to continue some other method of financing must be found.

Objectives: This study aimed to measure consumer preference for one of the two types of care offered in the SugarCare study, the control/standard and the intervention/enhanced service; the strength of that preference; and participants' willingness to pay (WTP) for their preferred care.
\end{abstract}

Methods: SugarCare was a parallel groups, control versus intervention, repeated measures design conducted in three areas of NSW, Australia. Patients in the Intervention group (enhanced care) had one initial visit to the pharmacy with six follow up visits over approximately 9 months. At these visits blood glucose was downloaded and patient care issues addressed. At the end of the service, a survey instrument was mailed to the intervention and control participants who were asked to read it and then expect a telephone call within 2 weeks of receipt. Responses were requested over the phone and the survey instrument completed by the researcher. WTP data were collected using a modified payment card method.

Results: Overall, 44/75 (59\%; 47\%-70\% 95\%Cl) respondents expressed a preference for Scenario B (the enhanced care) while 31/75 (41\%; 31\%-52\% $95 \% \mathrm{Cl}$ ) preferred Scenario A (standard care) however, the difference was not statistically significant. The median maximum WTP was AUD10 for the enhanced care and AUD3.50 for the standard care $(p<0.03)$.

Conclusions: While the WTP values expressed were significantly higher for the enhanced care they did not match with the cost providing that diabetes care. Discrete choice analysis has the potential to overcome some of the difficulties encountered with the contingent valuation technique used here. Further research is required before WTP values

\footnotetext{
* Susan TAYLOR. B Pharm MSc PhD, Grad Cert Ed. Faculty of Pharmacy, The University of Sydney, NSW (Australia).

Fleur HOURIHAN. RN, BSc, MPH. Centre for Rural and Remote Mental Health, Orange NSW (Australia). Ines KRASS. B.Pharm,DHP,PhD, Grad Cert Ed. Faculty of Pharmacy, The University of Sydney, NSW (Australia). Carol ARMOUR. B Pharm (Hons), PhD. Faculty of Pharmacy, The University of Sydney, NSW (Australia).
}

such as these could be used with confidence to determine funding policy.

Keywords: Patient Satisfaction. Community Pharmacy Services. Cost-Benefit Analysis. Australia.

\section{MEDIDA DE LAS PREFERENCIAS DE LOS CONSUMIDORES POR LOS MODELOS DE CUIDADOS DIABÉTICOS PRESTADOS POR FARMACÉUTICOS}

\section{RESUMEN}

Se realizó la evaluación del programa de gestión de enfermedad para diabetes tipo 2, 'SugarCare'. En comparación con los cuidados normales, este programa ofrecía a los pacientes un seguimiento más próximo de la glucemia, consejo sobre hábitos de vida, etc. El estudio SugarCare estuvo financiado por una beca, opero si se quiere que los cuidados continúen debe encontrarse otro método de financiación.

Objetivos: Este estudio pretendió medir las preferencias de los consumidores por uno de los dos tipos de cuidados ofrecidos en el estudio SugarCare, el control/estándar y el servicio intervención/avanzado; la fuerza de esas preferencias; y la voluntad de los participantes de pagar (WTP) por el cuidado preferido.

Métodos: SugarCare era un diseño en grupos paralelos, control contra intervención, con mediciones repetidas en tres áreas de New South Wales (Australia). Los pacientes en el grupo intervención (cuidados elevados) tenían una visita inicial a la farmacia con seis visitas de seguimiento durante aproximadamente 9 meses. En esas visitas, se medía la glucemia y se resolvían problemas en de los pacientes. Al final del servicio, se envió un cuestionario a los participantes control e intervención y se les pedía que lo leyesen y esperasen una llamada de teléfono a las dos semanas de recibirlo. Se solicitaban las respuestas al teléfono y el investigador completaba el cuestionario. Los datos de WTP se recogieron utilizando un método de tarjeta de pago modificado.

Resultados: 44/75 respondentes $(59 \% ; 47 \%-70 \%$ 95\% CI) expresó preferencias por el escenario B (cuidados avanzados) mientras que 31/75 (41\%; $31 \%-52 \%$ 95CI) prefirió el escenario A (cuidaos estándar), sin embargo la diferencia no fue estadísticamente significativa. La mediana del WTP máximo fue de 10 dólares australianos (AUD) para los cuidados avanzados y de 3,30AUD para los cuidados estándar $(\mathrm{p}<0,03)$. 
Conclusiones: Mientras que los valores de WTP expresados eran significativamente más altos para los cuidados avanzados, no encajaban con el coste de proporcionar esos cuidados diabéticos. El análisis de selección discreta tiene la posibilidad de superar algunas de las dificultades encontradas con la técnica de evaluación de contingencia utilizada aquí. Se necesitan investigaciones adicionales antes de que los valores de WTP como estos puedan ser utilizados con confianza para determinar políticas de financiación.

Palabras clave: Satisfacción de los pacientes. Servicios de farmacias comunitarias. Análisis coste-beneficio. Australia.

\section{INTRODUCTION}

Currently in Australia there are approximately 900,000 people with type 2 diabetes mellitus, $4.3 \%$ of the national population. ${ }^{1}$ It is predicted that, as these factors increase in our society, so too will the prevalence of type 2 diabetes. The cost of managing the disease and its complications is likely to exceed 1billion Australian dollars (AUD) annually in the next decade. Hence diabetes has been identified as a health priority world wide and a national health priority area. ${ }^{1}$

Interventions which have the potential to improve the management of diabetes and delay the onset of its complications have been encouraged because they are bound to reduce costs for the health care system. The literature reports numerous examples of positive health outcomes such as reduced incidence of hospital admissions and medical contacts when pharmacists provide professional types of care in controlled research situations. ${ }^{2}$ Significant improvements in glycaemic control have also been demonstrated. ${ }^{3-5}$

Given the potential contribution of pharmacists in Australia, a disease management program entitled 'SugarCare' was conducted as a pilot study by the Faculty of Pharmacy at the University of Sydney. This was done through 9 community pharmacies in one state of Australia, NSW, the most highly populated state. ${ }^{6}$ Compared with the standard care offered by pharmacists, this program offered patients much closer monitoring of their blood glucose levels, counselling about lifestyle, diet and exercise plus personal encouragement to maintain good habits in these areas.

In Australia, in order to convince the government of the benefits of professional types of care provided in community pharmacies, evidence of the benefit of a particular program and the value placed upon it must be provided before remuneration for the care is considered. Economic evaluation can be used to provide such evidence but very few economic evaluations have been conducted in relation to community pharmacy based types of care to date ${ }^{7,8}$ and in particular, very few cost benefit analyses. As part of this pilot study, to test a community pharmacy disease management program, a cost effectiveness analysis was conducted from the perspective of the health care system. ${ }^{9}$ In this it was found that for the $0.5 \%$ reduction in glycosylated haemaglobin $(\mathrm{HbA} 1 \mathrm{c})$ achieved in the study, a key indication of improved glycaemic control, the incremental cost of the care was AUD391 per patient over nine months (AUD43 per month). In addition to the cost effectiveness analysis, a cost benefit analysis (CBA) was conducted from the perspective of the patient in a consumer preference survey and the latter is the focus of this report.

\section{Measuring Consumer Preference}

Several different approaches have been tried in order to incorporate consumer opinion into health care decision making. One approach commonly adopted has been to administer patient satisfaction surveys. ${ }^{10}$ However, patient satisfaction surveys have many limitations and provide little help in addressing policy questions. Firstly, patients generally report high levels of satisfaction with the care they receive and thus surveys do not discriminate between types of care. ${ }^{11}$ Secondly, if patients are asked to value their own care they may not be aware of alternatives and so are not in a position to express a preference for one option over another. ${ }^{12}$ Thirdly, patient satisfaction surveys do not incorporate the notion of opportunity cost i.e. in order to have more of one treatment or care it may be necessary to have less of another, due to the limitation of health care resources. ${ }^{12}$ In other words, a sacrifice may need to be made.

In contrast, measurement of consumer preference for specific realistic choices can provide health care decision makers with an estimate of the value placed by consumers on particular options, and can incorporate the notion of opportunity cost. In health economics four main methods have been used to elicit consumer preferences. These are the visual analogue scale, the standard gamble, the time trade-off and willingness to pay. ${ }^{13}$ The first three have been used within a cost utility framework and generally a utility score is obtained. Willingness to Pay, on the other hand, is used to estimate utility in monetary terms and has been used within a cost benefit framework. According to economic theory, the maximum amount of money a consumer is willing to pay for a product or service is an indicator of the utility or satisfaction that the commodity provides to the individual and offers a measure of what the consumer will sacrifice in order to have the care. In cost benefit analysis, costs are ideally measured as opportunity costs and benefits are measured as the maximum Willingness to Pay (WTP) for the product or care being evaluated and provide a single measure of benefit. ${ }^{14}$

Both revealed preference and stated preference techniques have been used within the CBA framework. ${ }^{15,16}$ Revealed preference techniques are used to measure observed behaviour, ie the choices consumers actually make in practice and their willingness to pay for those choices. However, such data are not always available. As a consequence, stated preference techniques have been developed to gain some insight into what 
consumers might do if such a new product were offered. Stated preference techniques rely on hypothetical behaviour in response to a survey instrument in which respondents are asked to place a monetary value on the products or types of care under investigation. ${ }^{17,18}$

The Contingent Valuation (CV) method has been used to assess the stated preference and WTP for a product, service or intervention. ${ }^{19}$ The technique is so called because the respondent is asked to consider the contingency that a market exists for the item being valued even though a true market does not actually exist, for example in the publicly funded health care system. Although the technique has been used in more than 40 studies in health ${ }^{20,21}$ (Diener et al 1998 Olsen) there is still no agreed methodology. ${ }^{22}$ What is clear, however, is that in line with economic principles, such studies should assess the incremental costs and incremental benefits ie the difference in both cost and benefit between the options being compared. ${ }^{14}$ In order to do this, ideally respondents need to be offered a choice, whether real or hypothetical, and asked to express a preference for one option. They then should be asked to express the strength of their preference in monetary terms. ${ }^{17,23}$

A technique used more recently to elicit consumer preference in health is discrete choice analysis (also referred to in the literature as conjoint analysis, discrete choice modeling, discrete choice experiment, and stated preference discrete choice experiment). Discrete choice analysis is an appealing method to economists because it incorporates the notion of opportunity cost. ${ }^{24}$ Here consumers are presented with hypothetical scenarios and are asked to choose between products which are described in terms of different attributes. They are asked to trade off the levels of the attributes and the relative importance of these attributes can then be elicited. ${ }^{24}$ If cost is added as an attribute then the respondents' WTP can be assessed without a direct question being asked. ${ }^{17}$ The type of question posed to estimate WTP in discrete choice analysis may be more realistic than asking individuals directly in an open ended or payment card type WTP question.

However, several objections to the use of WTP techniques in health have been raised. ${ }^{25}$ One objection is that, as health care systems in most countries are publicly funded, there is some concern that respondents may assume a user pays system will be introduced if WTP questions are asked. This can lead to protest votes, or zero valuations, even from hypothetical statements. ${ }^{19,26}$ Another objection is that, because in a publicly funded health care system people do not pay, a Willingness to Pay question may not seem realistic and may make it difficult for respondents to distinguish between the cost of a product or care and the value they would place upon it. ${ }^{12}$

In addition, consumers' preferences and WTP values may be strongly influenced by the care they have actually experienced. ${ }^{11,23}$ This situation presents challenges in pharmacy practice research where frequently we may wish to evaluate a new pharmacy service compared with an existing service and incorporate feedback from patients. Invariably studies will involve an Intervention group and Control group but only those in the Intervention group will experience the new service. This study provided an opportunity to explore some of these methodological issues in an Australian context but may have relevance in similar health care systems world wide, and the contingent valuation technique was chosen to elicit consumer preferences.

The aim of this study was to gather evidence within a health economics framework of the benefit (or disbenefit) of the enhanced diabetes care provided by community pharmacies compared with the standard care provided.

The first objective was to measure the level of satisfaction patients expressed in relation to the diabetes care they received in the community pharmacy overall and also their level of satisfaction with particular aspects of the care. The second objective was to ascertain which of two types of care patients preferred for their type 2 diabetes mellitus and the strength of that preference compared with other types of care (in relation to their diabetes) with which they were familiar, such as a visit to the general medical practitioner. The third objective was to ascertain how much participants valued the care they preferred in terms of Willingness to Pay for it.

\section{METHODS}

\section{The SugarCare Project}

SugarCare was a parallel groups, control versus intervention, repeated measures design conducted in three areas of NSW. Two were metropolitan sites (one of which was a diabetes clinic) and one was a rural site, for both the Control and Intervention groups. Patients were recruited into the study by the participating pharmacists. ${ }^{6}$ Pharmacists in the Intervention group underwent a training program which has been reported elsewhere. ${ }^{27}$ In addition, on site follow up support was offered to these pharmacists by the research team.

The SugarCare care for patients in the Intervention group consisted of one initial visit of the patient to the pharmacy with six follow up visits over approximately 9 months. At the first visit patients were asked to complete questionnaires on quality of life, well being and medication use. These questionnaires were completed at the end of the nine months also. All patients were given a Medisense meter $(\mathrm{Rx})$ for the measurement of blood glucose. At each visit to the pharmacy, approximately once a month, the patients downloaded their blood glucose measurements into a computer and received a print out of the readings. The results were discussed and feedback provided. As part of the care any problems identified were addressed by the pharmacist and a medication review was undertaken. A report of this review was sent to the patient's general medical practitioner (GP). Clinical information such as HbA1c, blood pressure, lipids and Body Mass Index were collected at the beginning and end of the project for 
both Intervention and Control groups. Otherwise patients in the Control group received no further intervention above the normal care delivered by their pharmacist.

Ethics approval was obtained from the Human Resource Ethics Committee of the University of Sydney and the study was conducted in 2002.

\section{The Consumer Preference Survey}

\section{Recruitment of patients}

Because the model of the diabetes clinic care was different from that at the community sites, only patients recruited through the community sites were included in this survey. They were approached by their pharmacist during their final visit in the SugarCare study and those who agreed to participate signed a consent form. The survey was then mailed to the participants who were asked to read it and then expect a telephone call within 2 weeks of receipt. At the time of the call the questions were asked over the telephone and responses written down during the process.

\section{The Survey Instrument}

The instrument consisted of a description of two types of care offered by community pharmacists for the management of type 2 diabetes mellitus entitled Scenario A and Scenario B (Appendix 1). Respondents were asked how satisfied overall they were with the care they received and how satisfied they were with different aspects of the care. They were asked to rate their responses on a Likert type scale of 1 to 5 , from 1 "not very satisfied" to 5 "very satisfied". Following this they were asked whether they would prefer to receive the care described in Scenario A or Scenario B.

A variant of the payment card method $^{28}$ was used to assess WTP. Respondents were first asked to compare the value they placed on the pharmacy care with the value of having their blood pressure or cholesterol measured, with a visit to the GP and with a visit to a diabetes medical specialist with no monetary amounts suggested. They were then asked to state an amount they would be willing to pay per month for their preferred care compared with an approximate cost of the comparison types of care (AUD3.50, AUD10, AUD30 or AUD60). Once the patient stated an amount, the researcher asked them, through an open ended follow up question, to state the absolute maximum they would be willing to pay.

Following this, patients were asked questions about their demographic characteristics such as age, gender, highest level of education, household income, main activity, health insurance status, current monthly spending on diabetes, care model actually received and whether they were a concession card holder for prescriptions or not.

\section{Data Analysis}

After coding and entry, data were analysed using SPSS Version 17. Continuous, normally distributed data were reported as mean (SD), continuous not normally distributed data as median (IQR) and categorical data as frequencies and percentage.
Means of continuous data were compared using Student's $t$ test. The Mann-Whitney $U$ test for independent samples was used for between group comparisons of continuous data which were not normally distributed. Categorical data were compared using Pearson's chi-square statistic. Single proportions were compared by calculating the mean and $95 \%$ confidence intervals.

Potential influences on patient preference such as age, gender, type of care received (Intervention vs Control), years since diagnosis, level of education and household income were initially examined using univariate analysis to be followed by logistic regression if more than 1 factor was found to be statistically significant. Validity of the WTP question was tested by exploring the relationship between income and WTP values using the Chi-Square test for linear by linear association, with a positive relationship expected. All monetary values were expressed in 2002 Australian dollars.

\section{RESULTS}

\section{Response Rate}

A total of 128 patients were recruited by the pharmacists in the Intervention group of SugarCare and a total of 111 patients by the pharmacists delivering the standard care in the Control group. Of these, a total of $143 / 239(59.8 \%)$ subjects were eligible to participate in the WTP study (rural and metropolitan participants who completed the SugarCare project delivered through community practice sites rather than the diabetes clinics). $95 / 143(66.4 \%)$ gave signed consent to participate in the telephone survey and 78 actually attempted the survey (47 who had been included in the Intervention group and 31 in the Control group) giving a response rate of $54.5 \%(78 / 143)$. However, only $75 / 143(51.7 \%)$ respondents, [45/143 (31.5\%) Intervention group and 30/143 (20.7\%) Control group] completed the WTP section and so all results presented are for this data set.

Reasons given by those who gave signed consent but who did not attempt the survey $(17 / 143 ; 11.9 \%)$ included poor English (3/17); hospitalisation / illness $(2 / 17)$; out of area temporarily (2/17); moved from area (2/17); still at same address but phone disconnected (1/17); phone out of order or constantly engaged (1/17); unable to contact $(6 / 17)$. The reasons for non participation of the other 48 eligible patients are not known.

\section{Demographic characteristics of the participants}

The demographic characteristics of Intervention and Control group patients who participated in the WTP study are presented in Table 1, however not all participants answered every question. As the data were not normally distributed median values and inter-quartile ranges (IQR) of continuous variables have been used for comparison rather than the mean values. The median age of participants in the Intervention group was 62 years compared with 66 years for the Control group while the median time since the onset of diabetes was 6 and 5 years respectively. There were no significant between group differences in any of the characteristics compared. 


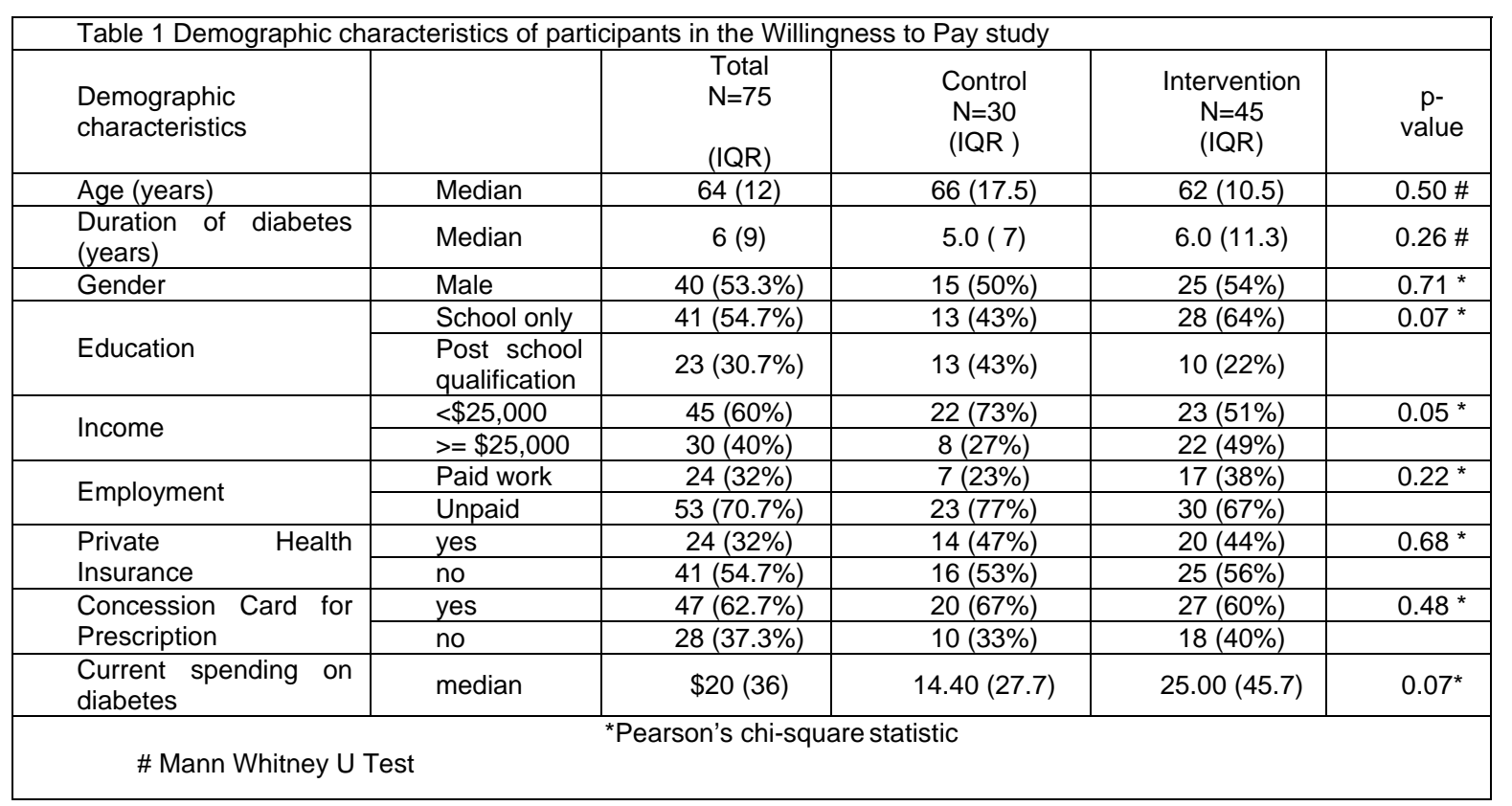

\begin{tabular}{|c|c|c|c|c|}
\hline $\begin{array}{l}\text { "Satisfied" or "Very Satisfied" with aspects of diabetes care } \\
\text { received in the community pharmacy in the study period }\end{array}$ & $\begin{array}{r}\text { Total } \\
\mathrm{N}=75\end{array}$ & $\begin{array}{c}\text { Control } \\
\mathrm{N}=30\end{array}$ & $\begin{array}{l}\text { Intervention } \\
\mathrm{N}=45\end{array}$ & $P$ value \\
\hline Overall diabetes care & $\begin{array}{c}67 \\
(89.3 \%) \\
\end{array}$ & $\begin{array}{c}25 \\
(83.3 \%) \\
\end{array}$ & $\begin{array}{c}42 \\
(93.3 \%) \\
\end{array}$ & 0.08 \\
\hline Information about medicine & $\begin{array}{c}61 \\
81.3 \% \\
\end{array}$ & $\begin{array}{c}22 \\
(73.3 \%) \\
\end{array}$ & $\begin{array}{c}39 \\
(86.7 \%) \\
\end{array}$ & 0.16 \\
\hline Discussion about medicines & $\begin{array}{c}47 \\
62.7 \% \\
\end{array}$ & $\begin{array}{c}17 \\
56.6 \% \\
\end{array}$ & $\begin{array}{c}30 \\
66.7 \%\end{array}$ & $P<0.01$ \\
\hline Information about diet & $\begin{array}{c}39 \\
52 \%\end{array}$ & $\begin{array}{c}8 \\
26.7 \%\end{array}$ & $\begin{array}{c}31 \\
68.9 \%\end{array}$ & $P<0.000$ \\
\hline Information about exercise & $\begin{array}{c}40 \\
53.3 \%\end{array}$ & $\begin{array}{c}7 \\
35 \% \\
\end{array}$ & $\begin{array}{c}33 \\
73.3 \% \\
\end{array}$ & $P<0.000$ \\
\hline Measurement of blood glucose & $\begin{array}{c}45 \\
60 \% \\
\end{array}$ & $\begin{array}{c}1 \\
3.3 \%\end{array}$ & $\begin{array}{c}44 \\
97.8 \%\end{array}$ & $P<0.000$ \\
\hline Management of medication/disease problems & $\begin{array}{c}49 \\
65.3 \%\end{array}$ & $\begin{array}{c}12 \\
40 \%\end{array}$ & $\begin{array}{c}37 \\
82.2 \%\end{array}$ & $P<0.000$ \\
\hline Discussion of diabetes and blood sugar & $\begin{array}{c}44 \\
58.7 \% \\
\end{array}$ & $\begin{array}{c}11 \\
36.7 \% \\
\end{array}$ & $\begin{array}{c}33 \\
73.3 \% \\
\end{array}$ & $P<0.000$ \\
\hline Encouragement and support to change habits & $\begin{array}{c}53 \\
70.7 \%\end{array}$ & $\begin{array}{c}11 \\
36.7 \%\end{array}$ & $\begin{array}{c}42 \\
93.3 \%\end{array}$ & $P<0.000$ \\
\hline
\end{tabular}

\section{Satisfaction with care received}

A majority of both Control group patients (25/30 $(83 \%))$ and Intervention group patients (42/45 $(93 \%))$ were either "very satisfied" or "satisfied" overall with the care they received $(p=0.08)$. (Table $2)$. Patient groups were also equally satisfied with the information they received about their medicines (73\% Control vs 87\% Intervention; $p=0.16$ ). However, a significantly higher proportion of patients in the Intervention group were either "satisfied" or "very satisfied" with the discussion they had with the pharmacist about their medicines, information received on diet and exercise, measurement of blood sugar, the management of their medication/disease problems, discussion of diabetes and blood sugar and the encouragement and support they received from the pharmacist to change their habits (Table 2).

\section{Patient preference for diabetes care description}

Overall, 44/75 (59\%; 47\%-70\% 95\%Cl) respondents expressed a preference for Scenario B (the enhanced care) while $31 / 75 \quad(41 \% ; 31 \%-52 \%$ $95 \% \mathrm{Cl}$ ) preferred Scenario A (standard care). However, the difference was not statistically significant. The majority of patients in the Intervention group expressed a preference for Scenario B $[34 / 45(75.6 \%)]$ ie the care they received in the study. Similarly the majority of the Control group expressed a preference for the care they received ie Scenario A [20/30 (66.7\%)] and this difference was statistically significant $(p<0.01$; Pearson Chi-Square). Of all the predictor variables tested only care received (Intervention or Control) had a significant influence on preference thus logistic regression analysis was not carried out. 


\begin{tabular}{|c|c|c|c|c|c|}
\hline $\begin{array}{l}\text { Value preferred care } \\
\text { as much as }\end{array}$ & & $\begin{array}{l}\text { Total } \\
\mathrm{N}=75\end{array}$ & $\begin{array}{l}\text { Control } \\
\mathrm{N}=30\end{array}$ & $\begin{array}{l}\text { Intervention } \\
\mathrm{N}=45\end{array}$ & $P$ value \\
\hline \multirow{3}{*}{$\begin{array}{l}\text { BP or Cholesterol } \\
\text { measurement }\end{array}$} & Yes & 32 (42.7\%) & $8(26.7 \%)$ & 24 (53.3\%) & \multirow[t]{3}{*}{$0.48^{*}$} \\
\hline & No & 2 & $1(3.3 \%)$ & $1(2.2 \%)$ & \\
\hline & Missing & 41 & $21(70 \%)$ & 20 (44.4\%) & \\
\hline \multirow[t]{3}{*}{ Visit to GP } & Yes & $50(66.7 \%)$ & $17(56.7 \%)$ & $33(73.3 \%)$ & \multirow[t]{3}{*}{$0.07^{*}$} \\
\hline & No & 21 & $12(40 \%)$ & $9(20 \%)$ & \\
\hline & Missing & 4 & 1 (3.3\%) & $3(6.7 \%)$ & \\
\hline \multirow{3}{*}{$\begin{array}{l}\text { Visit to Diabetes } \\
\text { Medical Specialist }\end{array}$} & Yes & 19 (25.3\%) & $2(6.7 \%)$ & $17(37.8 \%)$ & \multirow[t]{3}{*}{$0.005^{*}$} \\
\hline & No & 19 & 10 (33.3\%) & $9(20 \%)$ & \\
\hline & Missing & 37 & $18(60 \%)$ & $19(42.2 \%)$ & \\
\hline
\end{tabular}

\begin{tabular}{|c|c|c|c|c|}
\hline Preferred Care & Maximum WTP & $\begin{array}{l}\text { Total } \\
\mathrm{N}=75\end{array}$ & $\begin{array}{l}\text { Control } \\
\mathrm{N}=30\end{array}$ & $\begin{array}{l}\text { Intervention } \\
\mathrm{N}=45\end{array}$ \\
\hline \multirow{7}{*}{$\begin{array}{l}\text { Scenario A } \\
\text { (Standard Care) }\end{array}$} & $\$ 0$ & 10 & 6 & 4 \\
\hline & $\$ 3.50$ & 6 & 5 & 1 \\
\hline & $\$ 5$ & 3 & 2 & 1 \\
\hline & $\$ 8$ & 1 & 0 & 1 \\
\hline & $\$ 10$ & 8 & 6 & 2 \\
\hline & $\$ 15$ & 2 & 1 & 1 \\
\hline & $\$ 30$ & 1 & 0 & 1 \\
\hline \multicolumn{2}{|l|}{ Total Number } & 31 & 20 & 11 \\
\hline & Median Max WTP & $\$ 3.50(0-10) \#$ & $\$ 3.50(0-10)$ * & $\$ 5(0-10)$ * \\
\hline \multirow{11}{*}{$\begin{array}{l}\text { Scenario B } \\
\text { (Enhanced Care) }\end{array}$} & $\$ 0$ & 7 & 2 & 5 \\
\hline & $\$ 3.50$ & 7 & 2 & 5 \\
\hline & $\$ 5$ & 2 & 0 & 2 \\
\hline & $\$ 6$ & 1 & 0 & 1 \\
\hline & $\$ 8$ & 1 & 1 & 0 \\
\hline & $\$ 10$ & 17 & 5 & 12 \\
\hline & $\$ 15$ & 1 & 0 & 1 \\
\hline & $\$ 20$ & 3 & 0 & 3 \\
\hline & $\$ 30$ & 3 & 0 & 3 \\
\hline & $\$ 50$ & 1 & 0 & 1 \\
\hline & $\$ 100$ & 1 & 0 & 1 \\
\hline \multicolumn{2}{|l|}{ Total Number } & 44 & 10 & 34 \\
\hline & Median Max WTP & $\$ 10(3-10) \#$ & $\$ 9(2.65-10)$ ** & $\$ 10(3.5-16.3)^{* *}$ \\
\hline $\begin{array}{ll}\text { Preference } & \text { Groups } \\
\text { Combined } & \\
\end{array}$ & Median Max WTP & 75 & $\$ 4.25(0-10)^{\wedge}$ & $\$ 10(3.5-12.5)^{\wedge}$ \\
\hline \multicolumn{5}{|c|}{$\begin{array}{ll}* & \text { not significant; } \\
* * & \text { not significant } \\
\# & \mathrm{p}=0.03 \\
\wedge & \mathrm{p}=0.06 \\
\end{array}$} \\
\hline
\end{tabular}

\section{Valuation of preferred care compared with other health types of care}

When asked to compare the value they placed on their preferred diabetes care in the pharmacy with the value they placed on having their blood pressure or cholesterol measured, or a visit to the GP or a visit to a diabetes specialist, the majority of patients valued their preferred care the same as a visit to the GP. Although a higher proportion of the Intervention group valued their preferred care the same as a visit to the GP than patients in the Control group [33/45 (73\%) vs $17 / 30 \quad(57 \%)$ respectively] the difference was not statistically significant $(p<0.07)$ ) (Table 3$)$. However, there was a statistically significant difference in the proportion of the Intervention group who valued their preferred care as much as a diabetes medical specialist compared with the Control group [17/45 (38\%) vs $2 / 30(7 \%) ; p<0.005]$.

\section{Willingness to Pay}

Seventy five patients gave a monetary valuation for their preferred care, 45 in the Intervention group and 30 in the Control group (Table 4). The median maximum WTP for preferred care for the Intervention group overall was AUD10 (IQR=9) whereas that for the Control group overall was AUD4.25 (IQR=10). The difference between the two approached but did not reach significance at the $5 \%$ level $(p=0.058)$.

The median maximum WTP stated by the 31 respondents who expressed a preference for Scenario A was AUD3.50 and for the 44 respondents who expressed a preference for Scenario B the amount was AUD10. This difference was statistically significant $(p<0.03)$ indicating that the value placed on Scenario $B$ as preferred care, was higher than the value placed on Scenario $A$.

However 17 participants gave a zero valuation. The proportion who valued their preferred care at AUD0 
was greater in the group preferring Scenario A (Standard Care) 10/30 (32.3\%) compared with $7 / 44$ $(15.9 \%)$ (Scenario B) but the difference was not statistically significant $(p<0.1)$. Income had a statistically significant influence on maximum WTP for preferred care $(p<0.01)$ (Table 5).

\begin{tabular}{|c|c|c|c|c|}
\hline $\begin{array}{l}\text { Maximum Willingness } \\
\text { to Pay }\end{array}$ & Income $<\$ 25,000$ & Income $\$ 25,000$ to $\$ 50$ & Income $>\$ 50,000$ & $\begin{array}{l}\text { Total Number of } \\
\text { Responses }\end{array}$ \\
\hline$\$ 0$ & 9 & 7 & 0 & 16 \\
\hline$\$ 3.50$ & 9 & 4 & 0 & 13 \\
\hline$\$ 5.00$ & 3 & 0 & 2 & 5 \\
\hline$\$ 6.00$ & 0 & 1 & 0 & 1 \\
\hline$\$ 8.00$ & 2 & 0 & 0 & 2 \\
\hline$\$ 10,00$ & 17 & 7 & 1 & 25 \\
\hline$\$ 15.00$ & 2 & 0 & 1 & 3 \\
\hline$\$ 20.00$ & 1 & 1 & 1 & 3 \\
\hline$\$ 30.00$ & 1 & 1 & 2 & 4 \\
\hline$\$ 50.00$ & 0 & 0 & 1 & 1 \\
\hline$\$ 100.00$ & 0 & 0 & 1 & 1 \\
\hline $\begin{array}{l}\text { Total Number of } \\
\text { Responses }\end{array}$ & 44 & 21 & 9 & 74 \\
\hline
\end{tabular}

\section{DISCUSSION}

The majority of the 75 participants were either "satisfied" or "very satisfied" overall with the diabetes care they received in their community pharmacy as part of this study. Although a higher proportion of respondents, $59 \%(47 \%-70 \% 95 \% \mathrm{Cl})$, expressed a preference for Scenario B (the enhanced care) compared to $41 \%(31-52 \% 95 \% \mathrm{Cl})$ who preferred Scenario A (standard care) the difference was not statistically significant. However, preference was significantly influenced by the type of care actually received, with a higher proportion of the Intervention group preferring Scenario B (76\%) and a higher proportion of the Control group preferring Scenario A $(67 \%, p<0.001)$.

The majority of respondents valued their preferred care the same as a visit to the GP with no difference between Intervention and Control groups detected. However, there was a statistically significant difference in the proportion of the Intervention group who valued their preferred care as much as a diabetes medical specialist compared with the Control group [(38\%) vs $(7 \%) ; \quad p<0.005]$. Nevertheless, it should be noted that there was a high number of missing responses to this question in both groups.

The median maximum Willingness to Pay value expressed for preferred care based on the descriptions of Scenario A and Scenario B was significantly higher for Scenario $B$ than for Scenario A (standard care) (AUD10 vs AUD3.50 respectively; $\mathrm{p}<0.03)$. There were no significant differences between the Intervention and Control groups in this regard (Table 4). Income was found to have a positive correlation with WTP values overall but the sample size was too small to test this relationship for treatment or preference groups.

Thus in terms of the original study aim and objectives, measuring overall satisfaction with care received did not discriminate between the two types of care and would not provide convincing evidence of the value of the enhanced service offered. However, measurement of satisfaction of the different aspects of care certainly revealed a high degree of satisfaction in the Intervention group with the added features in the enhanced care such as measurement and discussion of blood glucose level.

Measurement of consumer preference also did not discriminate between the two levels of care and was significantly influenced by experience of care received, with the majority of patients choosing the type of care they had received. While the majority of Intervention group could compare the enhanced care to that which they had received in the past and expressed a preference for it, the majority of Control group could not do this or even imagine the service well enough to express a preference for it, despite the lengthy description given. They were satisfied with what they had. Ideally, to overcome the influence of care experienced, a randomized controlled, crossover trial would be conducted to ensure that all participants have experience of the all the services being compared. Given that it is frequently not possible to conduct cross-over studies for clinical, practical or funding reasons, controlling statistically for the influence of care received may be the best option.

Measurement of the strength of preference compared with other types of care (eg GP or diabetes medical specialist) showed some potential as a technique to help respondents differentiate between costs and values. However, a limitation found was that there were many missing responses to this question, and may indicate that the respondents found the comparison difficult to make.

Measurement of strength of preference in monetary terms revealed a small but significant difference in overall WTP values with respondents willing to pay more for Scenario B (enhanced care) than for Scenario A (standard care) and there were no differences in values between the Control and Intervention group. It should be acknowledged, however, that the sample size may have been too small to detect such a difference had it been there. Nevertheless, the contingent valuation technique would appear to have the most potential for discriminating between these two alternatives. 
However, a major limitation was noted in the application of the CV technique in that $17 / 75$ $(22.7 \%)$ respondents gave zero valuations, a high proportion compared with our previous study. ${ }^{29}$ The zero valuations may have been protest votes or may merely have reflected respondents' limited income and already extensive medical and pharmaceutical costs. Either way, the zero valuations have clearly lowered the average WTP values calculated and may indicate the difficulty of the technique in eliciting monetary values in a publicly funded health care system which truly reflect the strength of respondents' preferences for particular types of care. These low values may also have been influenced by the amounts suggested in the instrument which were biased towards the lower end of the range.

The monetary valuations expressed in this study are much less than the extra cost of providing the care (AUD43 per month) as calculated in the cost effectiveness analysis of the SugarCare project ${ }^{9}$ and application of the decision rule in CBA on pure economic grounds would dictate that the intervention should not be funded. ${ }^{14}$ However, the cost of the service is in the same range as other interventions currently subsidised by the Australian government, for example a course of drug treatment and the practice of partial subsidization, supplemented by a patient co-payment, is well established in the Australian health care system. Thus the contribution of AUD10 for the enhanced service suggested by participants in this study compared with AUD3.50 for the standard care may be a realistic expectation and is comparable to payment for other services offered.

Further investigation is required to develop techniques which elicit assessment of incremental benefit but do not at the same time make the exercise too difficult for respondents to comprehend and execute. Discrete choice analysis has the potential to overcome some of the difficulties encountered with the contingent valuation technique, in that consumers can be asked for a non-monetary valuation of a health care intervention or indirectly for their willingness to pay. ${ }^{30-36}$ Future studies could explore the use of this technique in relation to community pharmacy based clinical interventions.

\section{CONCLUSIONS}

Respondents in this study expressed higher WTP values for Scenario $B$, the description of the enhanced care offered as part of this study, than for Scenario A, the description of the standard care (AUD10 vs AUD3.50) and these values were the same whether the patient had experienced the enhanced care or not. However, these values were low and would not cover the cost of providing the service. Nevertheless they may serve as a useful guide to health care decision makers of the amount patients would be prepared to contribute as a copayment.

\section{CONFLICT OF INTEREST}

No funding was received for the manuscript however the SugarCare project was funded by the Commonwealth Government of Australia under the Second Community Pharmacy Agreement Research and Development Program of the Pharmacy Guild of Australia.

The valuation study was supported by the Sesqui New Staff Support Scheme of the University of Sydney.

\section{References}

1. Amos A, Zimmet P, McCarty D. The rising global burden of diabetes and its complications: Estimates and projections to the year 2010. Diabet Med. 1997;14:S7-S85.

2. Sczupak CA, Conrad WF. Relationship between patient-oriented pharmaceutical types of care and therapeutic outcomes of ambulatory patients with diabetes mellitus. Am J Hosp Pharm. 1977;34:1238-1242.

3. Jaber LA, Halapy H, Fernet M, Tummalapalli S, Diwakaran $\mathrm{H}$. Evaluation of a pharmaceutical care model on diabetes management. Ann Pharmacother. 1996;30:238-243.

4. Berringer R, Shibley MC, Cary CC, Pugh CB, Powers PA, Rafi JA. Outcomes of a community pharmacy-based diabetes monitoring program. J Am Pharm Assoc. 1999; 39(6):791-797.

5. Davidson MB, Karlan VJ, Hair TL. Effect of a pharmacist-managed diabetes-care program in a free medical clinic. Am J Med Qual 2000;15(4):137-142.

6. Armour C, Taylor S, Hourihan F, Smith C, Krass I. Pharmacists leading the way in diabetes care- disease state management. J Am Pharm Assoc.2004; 44(4):455-466.

7. Simeons S Economic evaluation of pharmacy practice: research informing policy. Int J Pharm Pract. 2008;16:337-338.

8. Scott A, Bond C, Inch J, Grant A. Preferences of community pharmacists for extended roles in primary care. Pharmacoeconomics. 2007; 25(9):783-792.

9. Taylor SJ, Milanova T, Hourihan F, Coleman C, Krass I, Armour CL. A cost effectiveness analysis of a community pharmacist-initiated disease state management care for type 2 diabetes mellitus. Int J Pharm Pract. 2005;13:33-40.

10. Hall J, Shiell A. What patients like about their medical care and how often they are asked: a meta-analysis of the satisfaction literature. Soc Sci Med. 1988;27: 935-939.

11. Ryan M, Scott DA, Bate A, van Teijlingen E, Russell EM, Napper M, Reeves $C$ and Robb C. Eliciting public preferences for health care: a systematic review and evaluation of methods. Health Technol Assess. 2001;5(5):1-186.

12. Donaldson, C. Willingness to pay for publicly provided health care. University of Aberdeen, Scotland, 1995

13. Torrance GW. Measurement of health state utilities for economic appraisal. J Health Econ. 1986;5(1):1-30 
14. Drummond MF, O'Brien B, Stoddart GL, Torrance GW. Methods for the Economic Evaluation of Health Care Programmes. Oxford: Oxford University Press, 1997.

15. Kroes EP, Sheldon RJ. Stated Preference Methods. J Transport Econ Policy 1988;(January):11-25.

16. Viscusi W. Labour market valuations of life and limb: empirical estimates and policy implications. Public Policy. 1978;26:359-389.

17. Ryan M. Using Consumer Preferences in health care decision making. Office of Health Economics, 1996.

18. Ryan M, Hughes J. Using conjoint analysis to assess women's preferences for miscarriage management. Health Econ. 1997;6:261-273.

19. Gafni A. Willingness To Pay - What's in a name? Pharmacoeconomics. 1998;14:465-470.

20. Diener A, O'Brien B, Gafni A. Health care contingent valuation studies: a review and classification of the literature. Health Econ., 1998;7:313-326.

21. Olsen JA, Smith RD. Theory versus practice: a review of "willingness to pay" in health and health care. Health Econ. 2001;10:39-52.

22. Klose T. The contingent valuation method in health care. Health Policy 1999;47(2):97-123.

23. Donaldson $C$, Shackley $P$, Abdalla M. Using willingness to pay to value close substitutes: carrier screening for cystic fibrosis revisited. Health Econ. 1997;6:145-159.

24. Ryan M. A role for conjoint analysis in technology assessment in health care? Int J Technol Assess Health Care. 1999;15:443-457.

25. Cookson R. Willingness to pay methods in health care: a skeptical view. Health Econ. 2003;12:891-894.

26. Johannesson $M$, Jonsson B. Economic evaluation in health care: is there a role for cost benefit analysis? Health Policy. 1991;17:1-23.

27. Gates B, Smith C, Krass I, Armour CL. Diabetes care in community pharmacy- a focus on training the pharmacist to deliver a specialised care. Aust J Pharm. 2001;82:504-508.

28. O'Brien B, Gafni A. When do the dollars make sense? Med Decis Mak 1996;16:288-299.

29. Taylor SJ, Armour CL. Measurement of consumer preference for treatments used to induce labour: a willingness-to-pay approach. Health Expect. 2000;3:203-216.

30. Ryan M, Gerard K, Amaya-Amaya M. Using Discrete Choice Experiments to Value Health and Health Care. Springer Berlin Heidelberg New York Ed 2008.

31. Payne K, Elliott R. Using discrete choice experiments to value preferences for pharmacy services. Int J Pharm Pract. 2005;13:9-20.

32. Ryan M. Discrete Choice Experiments in health care. BMJ. 2004;328:60-61.

33. Ryan M. Gerard K Using discrete choice experiments to value health care: current practice and future prospects. Appl Health Econ and Policy Anal. 2003;2:55-64.

34. Porteous T, Ryan M, Bond C, Hannaford P. Preferences for self-care or consulting a health professional for minor illness: A discrete choice experiment. Br J Gen Pract. 2006;56:911-917.

35. Gerard K, Salisbury C, D Street, Pope C, H Baxter. Is Fast Access to General Practice All That Should Matter? A Discrete Choice Experiment of Patients' Preferences. J Health Serv Res Pol. 2008;13:3-10.

36. Taylor SJ, Armour CL. Consumer preference for dinoprostone vaginal gel using stated preference discrete choice modeling. Pharmacoeconomics. 2003; 21:721-735. 


\begin{tabular}{|c|c|c|}
\hline \multicolumn{3}{|l|}{ Appendix 1} \\
\hline & Scenario A & Scenario B \\
\hline Supply of medication & $\begin{array}{l}\text { The pharmacist supplies the medication } \\
\text { and orders it for me if necessary. }\end{array}$ & $\begin{array}{l}\text { The pharmacist supplies the medication and } \\
\text { orders it for me if necessary. }\end{array}$ \\
\hline $\begin{array}{l}\text { Information about } \\
\text { medication }\end{array}$ & $\begin{array}{l}\text { The pharmacist explains how my } \\
\text { medication works and about the main side } \\
\text { effects. }\end{array}$ & $\begin{array}{l}\text { The pharmacist explains how my medication } \\
\text { works and about the main side effects. }\end{array}$ \\
\hline $\begin{array}{l}\text { Changes in medication } \\
\text { suggested to doctor }\end{array}$ & $\begin{array}{l}\text { The pharmacist does not usually suggest } \\
\text { any changes in my medication. }\end{array}$ & $\begin{array}{l}\text { The pharmacist reviewed all my medications } \\
\text { carefully and sometimes suggested to the } \\
\text { doctor a change in medication type or dose. }\end{array}$ \\
\hline Information about diet & $\begin{array}{l}\text { The pharmacist gives me some } \\
\text { information about diet. }\end{array}$ & $\begin{array}{l}\text { The pharmacist gives me a lot of helpful } \\
\text { information about diet and encourages me } \\
\text { every month to stick to the best diet for me. }\end{array}$ \\
\hline $\begin{array}{l}\text { Information about } \\
\text { exercise }\end{array}$ & $\begin{array}{l}\text { The pharmacist gives me some } \\
\text { information about exercise. }\end{array}$ & $\begin{array}{l}\text { The pharmacist gives helpful information about } \\
\text { exercise and encourages me every month to } \\
\text { stick to the best exercise program for me. }\end{array}$ \\
\hline $\begin{array}{l}\text { Measurement of blood } \\
\text { glucose }\end{array}$ & $\begin{array}{l}\text { I measure my blood glucose levels at } \\
\text { home then take the results to my doctor. }\end{array}$ & $\begin{array}{l}\text { I measure my blood glucose levels at home } \\
\text { using a meter. Every month I take the meter to } \\
\text { the pharmacy and the pharmacist puts the } \\
\text { results into the computer. We then look at the } \\
\text { results and I can see that my blood glucose } \\
\text { has gone down over time. This encourages me } \\
\text { to stick to my diet and exercise routine. } \\
\text { The pharmacist always explains to me that if } \\
\text { my blood glucose levels are in the right range I } \\
\text { will have less chance of complications. }\end{array}$ \\
\hline $\begin{array}{l}\text { Management of my } \\
\text { disease and any } \\
\text { problems }\end{array}$ & $\begin{array}{l}\text { If I have a problem about my medication } \\
\text { or diabetes I ask the pharmacist about it } \\
\text { but usually I would discuss problems with } \\
\text { my doctor. }\end{array}$ & $\begin{array}{l}\text { The pharmacist asks me every month if I have } \\
\text { any problems about my medications or about } \\
\text { my diabetes. If I do have a problem we discuss } \\
\text { it and find ways of managing the problem. }\end{array}$ \\
\hline
\end{tabular}

